Article

\title{
Water Quality Changes during Rapid Urbanization in the Shenzhen River Catchment: An Integrated View of Socio-Economic and Infrastructure Development
}

\author{
Hua-peng Qin ${ }^{1, *}$, Qiong Su ${ }^{1}$, Soon-Thiam Khu ${ }^{2}$ and Nv Tang ${ }^{1}$
}

1 Key Laboratory for Urban Habitat Environmental Science and Technology, School of Environment and Energy, Peking University Shenzhen Graduate School, Shenzhen 518055, China; E-Mails: joansusu@gmail.com (Q.S.); sapphiretang89@gmail.com (N.T.)

2 Faculty of Engineering and Physical Sciences, University of Surrey, Civil Engineering (C5), Guildford, Surrey GU2 7XH, UK; E-Mail: S.Khu@surrey.ac.uk

* Author to whom correspondence should be addressed; E-Mail: qinhp@pkusz.edu.cn; Tel./Fax: +86-755-2603-5291.

External Editor: Mario Tobias

Received: 24 August 2014; in revised form: 3 October 2014 / Accepted: 14 October 2014 /

Published: 23 October 2014

\begin{abstract}
Surface water quality deterioration is a serious problem in many rapidly urbanizing catchments in developing countries. There is currently a lack of studies that quantify water quality variation (deterioration or otherwise) due to both socio-economic and infrastructure development in a catchment. This paper investigates the causes of water quality changes over the rapid urbanization period of 1985-2009 in the Shenzhen River catchment, China and examines the changes in relation to infrastructure development and socio-economic policies. The results indicate that the water quality deteriorated rapidly during the earlier urbanization stages before gradually improving over recent years, and that rapid increases in domestic discharge were the major causes of water quality deterioration. Although construction of additional wastewater infrastructure can significantly improve water quality, it was unable to dispose all of the wastewater in the catchment. However, it was found that socio-economic measures can significantly improve water quality by decreasing pollutant load per gross regional production (GRP) or increasing labor productivity. Our findings suggest that sustainable development during urbanization is possible, provided that: (1) the wastewater infrastructure should be constructed timely and revitalized regularly in line with urbanization, and wastewater treatment facilities should be
\end{abstract}


upgraded to improve their nitrogen and phosphorus removal efficiencies; (2) administrative regulation policies, economic incentives and financial policies should be implemented to encourage industries to prevent or reduce the pollution at the source; (3) the environmental awareness and education level of local population should be increased; (4) planners from various sectors should consult each other and adapt an integrated planning approach for socio-economic and wastewater infrastructure development.

Keywords: water quality; wastewater infrastructure; socio-economic policy; urbanization; catchment

\section{Introduction}

Many catchments in developing countries are experiencing rapid urbanization [1,2]. These catchments are faced with the challenge of maintaining (or improving) water quality while allowing for economic growth and population expansion [3]. Understanding the characteristics and mechanisms of water quality changes in the catchment can help policy makers evaluate the effectiveness of water management measures, avoid repetition of past mistakes and create a sustainable development environment.

Many studies have investigated and characterized the changes in water quality during urbanization. Ren et al. [4] found that urbanization from 1947 to 1996 in Shanghai corresponded to a rapid degradation of water quality in the Huangpu River. A separate study in Shanghai found that water quality in the city center had deteriorated from the early 1980 s to the early 1990 s but has been improving since the 1990s [3]. Chang [5] reported that with rapid urbanization and economic development, the water quality of the Han River in Korea declined gradually during the 1960s and 1970s but improved after control measures were put in place in the 1980s. Kannel et al. [6] detected increasing phosphorus contents from 1999 to 2003 in the urban areas of the Bagmati River catchment, Nepal.

Studies have also been performed to determine the causes of water quality change in urbanized catchments [4,7-9]. It is well known that population growth and industrial activities are drivers of water quality change. Groppo et al. [10] found that population growth and increases in untreated sewage were the main causes of water quality deterioration in rivers in the State of Sao Paulo, Brazil. Ma et al. [11] found that sharp increases in industrial pollution and domestic discharge were the major causes of water quality deterioration in the Shiyang River, Northwest China. Suitable water management measures, however, may also be included in the urbanization process to mediate water quality deterioration [12] such as installing wastewater infrastructure (e.g., wastewater treatment plant (WWTP) and urban drainage system) to increase wastewater treatment capacity. Socio-economic policies such as industrial structure regulation, economic incentive and finance policies, command and control, and legal measures are able to improve water consumption efficiencies and reduce pollutant load generation $[13,14]$.

Although many policies and measures have been enacted, water quality degradation continues to be a serious problem in some rapidly urbanizing areas. For the past three decades, surface water deterioration has coincided with rapid economic growth in China despite the implementation of modern water management measures [15]. Many researchers found that such deterioration is due to the complex interaction between engineered infrastructures and social, economic, legal, and political issues during 
rapid urbanization $[16,17]$. However, most research addressed water quality change in urbanized areas rather than catchments in the process of rapid urbanization [6,10]. Furthermore, even fewer studies have investigated the integrated impact of socio-economic and infrastructure development on changes in water quality [16]. Current understandings of the impact of urbanization on water quality are mainly anecdotal. Further research is required to generate an integrated view of water quality changes, pollution generation in the socio-economic system and pollution control measures in the management system.

Using the Shenzhen River catchment in China as a case study, this paper will examine the water quality changes in the catchment during the rapid urbanization period of 1985 to 2009 based on measured water quality data and estimated pollutant loads. The objectives of this study are: (1) to characterize the water quality changes and better understand the factors that determine the changes in the catchment; (2) to evaluate the effects of infrastructure development and socio-economic policies on water quality changes; and (3) to propose possible solutions on water quality changes in the rapid urbanization catchment.

\section{Material and Methods}

\subsection{Study Area}

The Shenzhen River is located in a rapidly urbanizing coastal region of Southeast China and forms the administrative border between Shenzhen City and Hong Kong (Figure 1). The total catchment area of the Shenzhen River is $312 \mathrm{~km}^{2}$. The river is a typical tidal river and is $14 \mathrm{~km}$ long. The main river drains southwest into Deep Bay, which joins the Pearl River estuary on its seaward side. Three sampling stations, S1, S2 and S3, are located in the upper, middle and lower streams of the river, respectively (Figure 1). The catchment has a mild, subtropical maritime climate with a mean annual temperature of $22.4{ }^{\circ} \mathrm{C}$ and a mean annual precipitation of $1933 \mathrm{~mm}$.

Figure 1. Overview of the Shenzhen River catchment.

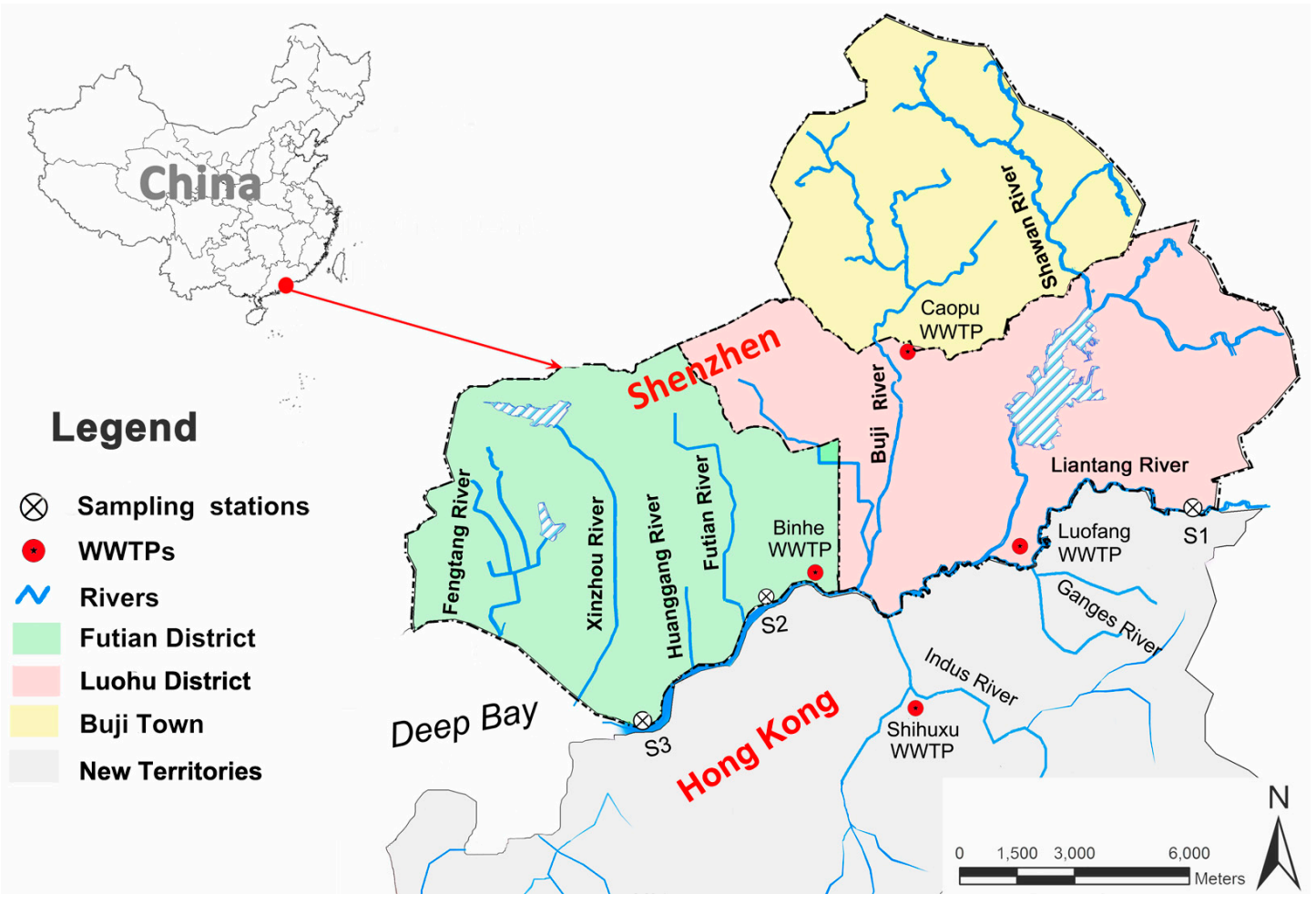


The northern catchment, with an area of $188 \mathrm{~km}^{2}$, includes three administrative areas of Shenzhen: Luohu District, Futian District, and Buji Town. Over the past three decades, this area has experienced rapid urbanization. Between 1980 and 2009, the area's gross regional product (GRP) increased from 0.4-116.3 billion yuan (using the 1990 price), total population increased from 0.16 million to 2.69 million and the ratio of built-up to developable land increased from $12.0 \%-91.9 \%$. In contrast, the southern catchment of the Shenzhen River belongs to the Northern New Territories of Hong Kong. Most of the area within the southern catchment is rural with low population densities.

\subsection{Water Quality Data}

The water quality in the Shenzhen River has been measured by the Environmental Monitoring Station of Shenzhen since 1985. The data set measured from 1985-2009 was used to characterize the water quality change during rapid urbanization. The water quality was measured bi-monthly from 1985-2002 and monthly after 2002. To consider the effects of tides, two water samples were collected during ebb and flood tides. Ten water quality parameters are considered in this study: $\mathrm{BOD}_{5}, \mathrm{NH}_{3}-\mathrm{N}$, TP, petroleum, volatile phenol $(\mathrm{V}-\mathrm{ArOH})$, hexavalent chromium $\left(\mathrm{Cr}^{6+}\right)$, mercury $(\mathrm{Hg})$, lead $(\mathrm{Pb})$, copper $(\mathrm{Cu})$ and cadmium $(\mathrm{Cd})$. These parameters are the target indicators in China's environmental monitoring system. The river is classified as a water body for landscape requirements. The maximum permitted concentrations (MPCs) for various water quality parameters are prescribed by the Environmental Quality Standard for Surface Water in China (GB 3838-2002). For example, MPCs for BOD, $\mathrm{NH}_{3}-\mathrm{N}$ and TP are $10 \mathrm{mg} / \mathrm{L}, 2 \mathrm{mg} / \mathrm{L}$ and $0.4 \mathrm{mg} / \mathrm{L}$, respectively. In order to obtain an overall understanding of the combined effect of the changes in the target indicator values a composite indicator-Water Pollution Index (WPI) - was used to assess the comprehensive status of the water quality of the Shenzhen River. The index is defined as follows [18,19]:

$$
W P I=\frac{1}{n} \sum_{i=1}^{n} C_{i} / S_{i}
$$

where $n$ represents the number of water quality parameters; $C_{i}$ is the average measured concentration of the $i$ th parameter, $\mathrm{mg} / \mathrm{L}$; and $S_{i}$ is the MPC for the $i$ th parameter. The water quality can be classified into six types by WPI: very pure, pure, moderately polluted, polluted, impure and heavily impure with corresponding WPI values of below $0.3,0.3-1.0,1.0-2.0,2.0-4.0,4.0-6.0$ and over 6.0, respectively [18]. Furthermore, to show the pollutants that most significantly reduce the overall water quality (in the sense of violating their objective levels), the contribution of each polluting substance to the summed pollution index of all pollutants is calculated as follows:

$$
K_{i}=\frac{C_{i} / S_{i}}{\sum_{n=1}^{i} C_{i} / S_{i}}
$$

where $K_{i}$ is the contribution of each substance to the summed pollution index. 


\subsection{Methods to Estimate the Pollutant Load}

The pollutant load discharged into the river is the direct driving factor of water quality change during urbanization. In the Shenzhen River catchment, however, the pollutant load has not been directly measured and therefore a simple method was proposed to estimate this discharge.

Reasons for change in pollutant load discharge during rapid urbanization are usually varied and complex. They are either directly or indirectly linked to social-economic development and engineering interventions. In this study, a cause diagram is used to break down broad items into increasingly finer levels of detail, and is also useful for identifying the causal relationships between items of interest.

Based on cause-and-effect analysis, a diagram was constructed to trace the causes of pollutant load changes in the Shenzhen River catchment. As shown in Figure 2, the pollutant load discharge into the river is related to the difference between the total pollutant load generated within the catchment and the pollutant load removed by wastewater infrastructure. Pollution is often categorized into point source and non-point source. However, water quality during wet periods in the Shenzhen River is much better than that during dry periods [20]. According to estimates by Liu and Lu [21], non-point source pollutant loads are much smaller than the pollutant loads from industrial and domestic sources in the catchment and therefore only point source pollution is considered in this study.

Figure 2. Cause diagram of water quality changes in the Shenzhen River catchment.

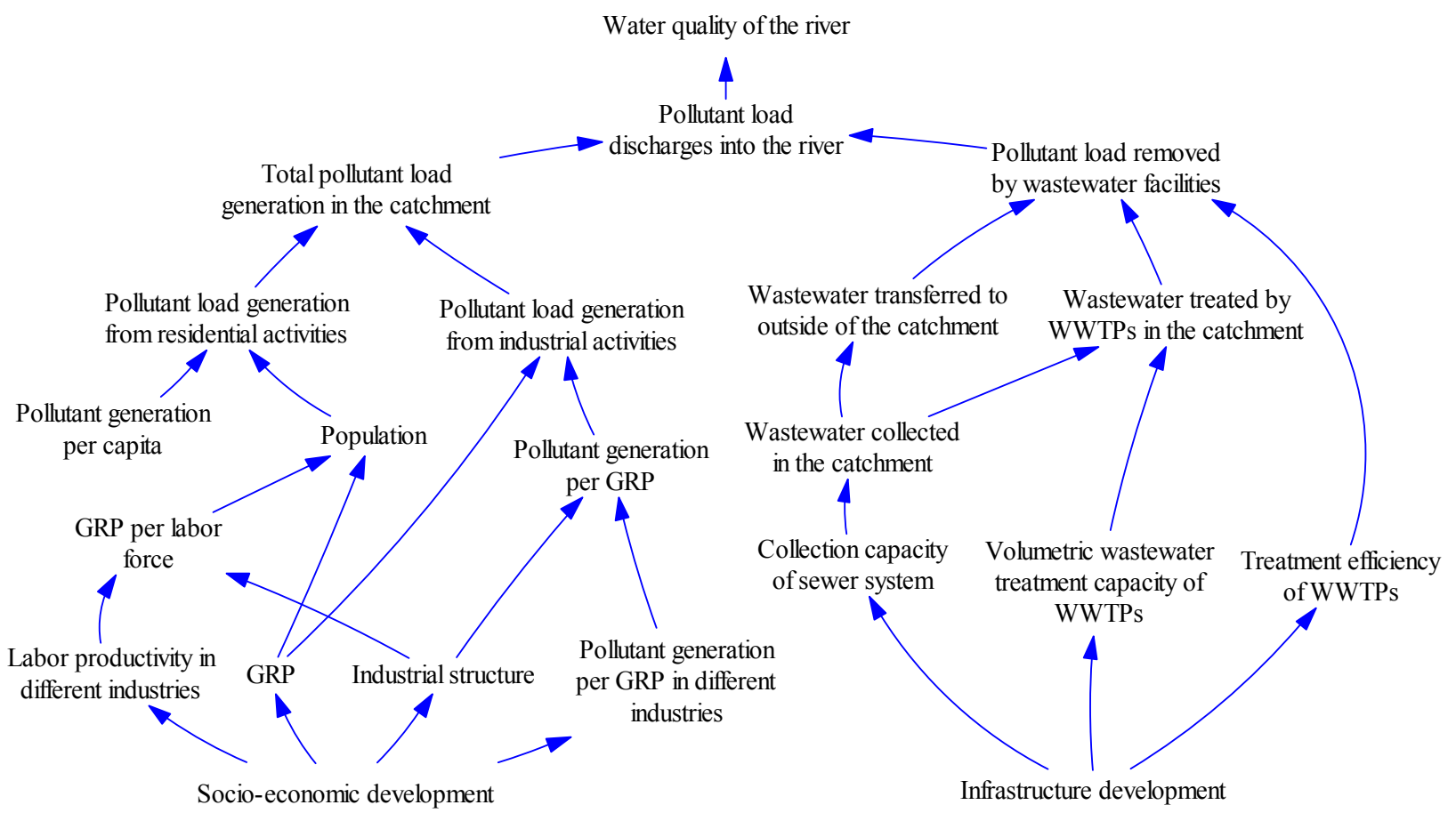

The pollutant load generation is affected by socio-economic development. Industrial wastewater is discharged by manufacturing and production processes and commercial enterprises. Pollution from industrial activities is estimated based on GRP and pollutant load per unit GRP. The respective equation can be expressed as follows:

$$
L G_{e, t}=G R P_{t}^{*} L O A D_{G R P, t}
$$


where $L G_{e, t}$ and $L O A D_{G R P, t}$ denote industrial pollutant load (tons) and the pollutant load per unit GRP in year $t$, respectively. $L O A D_{G R P, t}$ is a function of industrial structure and pollutant per GRP in different industries. The industry structures in the study area can be categorized into primary (e.g., agriculture), secondary (e.g., manufacturing) and tertiary (e.g., services) industries. Each industry type can be further sub-divided according to the primary factor in the production process. $L O A D_{G R P, t}$ can be expressed as follows:

$$
L O A D_{G R P, t}=\sum_{i}\left(P R O P_{i, t} * L O A D_{G R P i, t}\right)
$$

where $P R O P_{i, t}$ and $L O A D_{G R P i, t}$ are GRP proportion and the pollutant load per unit GRP of industry $i$ in year $t$, respectively. Therefore, pollutant load generation from industrial activities can be estimated by GRP, industrial structure and pollutant load per unit GRP of different industries. Furthermore, water pollutant loads from tertiary industries are usually identified as domestic pollution and are thus included in the estimation of pollutant generation in residential activities (Equation (5)). And thus Equations (3) and (4) were only applied to estimate pollutant load in the secondary industry in this study.

Domestic wastewater comes from residential sources, including toilets, sinks, baths and laundry. Pollution from residential activities is estimated according to the population size and pollutant load per capita. The respective equation can be expressed as follows:

$$
L G_{r, t}=\operatorname{Pop}_{t} * L O A D_{c a p, t}
$$

where $L G_{r, t}$ denotes residential pollutant load (tons) in year $t$; $L O A D_{c a p, t}$ denotes the pollutant load per capita, which is assumed to be constant in this study.

To understand the changes of pollution from residential activities, population growth during rapid urbanization should be further analyzed. Fertility, mortality and migration are principal determinants of population growth. However, migration accounts for a large percentage of total population in rapidly urbanizing areas (e.g., more than $80 \%$ in Shenzhen City, China in 2007). Population growth in an urbanizing catchment is mainly determined by the labor demand of economic development [13] and expressed as

$$
\operatorname{Pop}_{t}=R_{p o p, t} * G R P_{t} / L A B O R_{G R P, t}
$$

where $R_{p o p, t}$ is the ratio of a population to the number of labors at year $t$ in a catchment. LABORGRP,t is the GRP per labor force, which is a measurement of labor force productivity. LABORGRP,t is a function of industrial structure and labor productivity for different industries, and it can be expressed as follows:

$$
\operatorname{LABOR}_{G R P, t}=1 / \sum_{i}\left(\operatorname{PROP}_{i, t} / L A B O R_{G R P i, t}\right)
$$

where $L A B O R_{G R P i, t}$ denotes GRP per labor force of industry $i$ in year $t$.

However, with the development of wastewater infrastructure, the capacity for removal of the pollutant load has steadily increased. The pollutant load removed by wastewater infrastructure can be determined by the wastewater volume collected in the catchment and the pollutant removal rate of the WWTPs. In addition, some wastewater is transported out of the catchment and then discharged into the sea. Thus, the pollutant load removed by wastewater treatment or transfer facilities can be calculated by the following expression: 


$$
L R_{t}=\left(V_{p, t} * \alpha_{t}+V_{s, t}\right) * C_{w}
$$

where $L R_{t}$ is the pollutant load removed by wastewater infrastructure in year $t ; V_{p, t}$ and $V_{s, t}$ are the wastewater volume treated by WWTPs in the catchment and the volume transported out of the catchment in year $t$, respectively; $\alpha_{t}$ is the WWTPs' pollutant removal rate in year $t$; and $C_{w}$ is the averaged pollutant concentration of municipal wastewater.

The GRP, population, industrial structure and labor productivity in different industries are obtained from the Statistical Year Book of Shenzhen (1985-2009) [22]. The pollutant load per capita, pollutant load per unit GRP of different industries, and the status of wastewater infrastructure are obtained from published government reports [23-25].

\section{Results}

\subsection{Temporal Trend of Water Quality}

Water quality measured at the sampling station S3 (Figure 1) was used to calculate the WPI as it represents the effect of pollution discharges in the whole catchment on the water quality of the river. As shown in Figure 3, the annual average WPI varied between 1.6 and 2.2 from 1988-1995, decreased after 1996, and reached 1.5 in 2009.

Figure 3. Annual average WPI (Water Pollution Index) and relative contributions of each pollutant to WPI in the Shenzhen River.

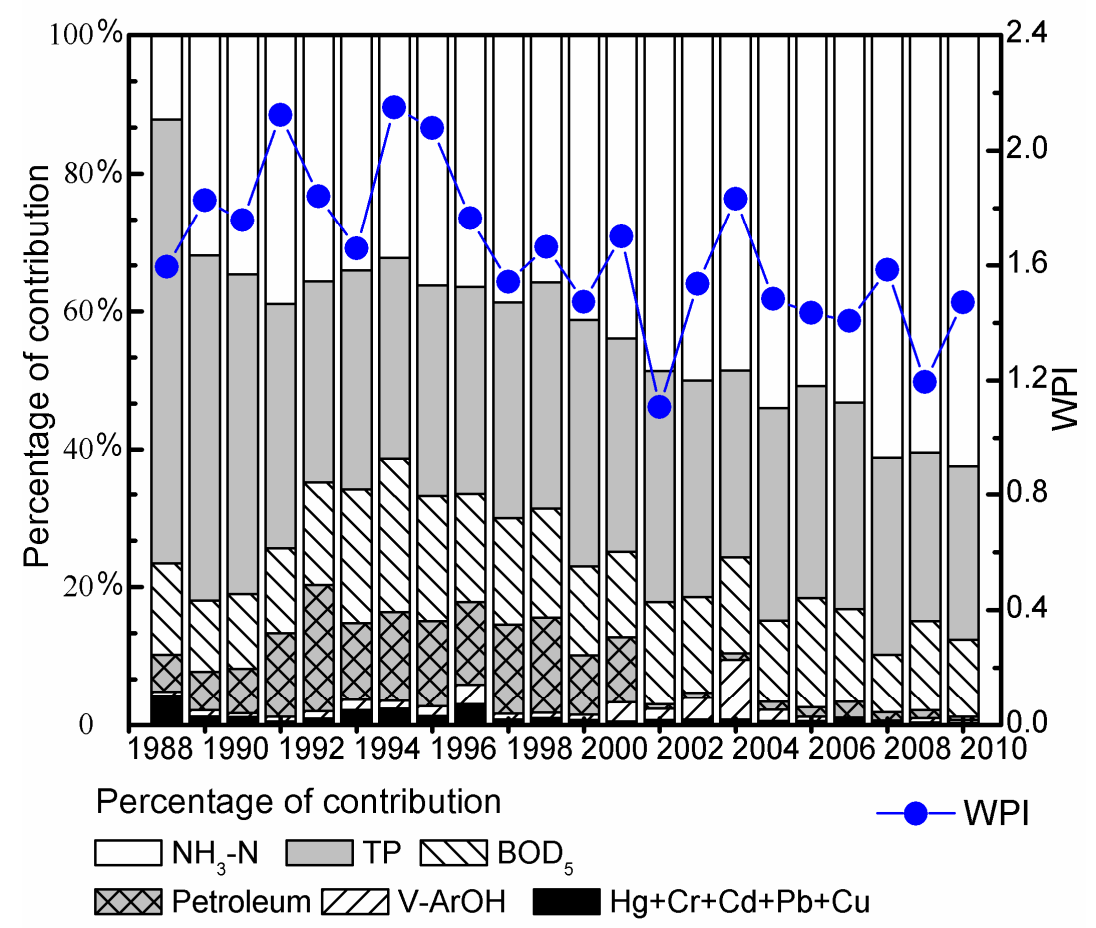

The contribution of each polluting substance to the WPI was calculated according to Equation (2). The results indicated that the main pollutants in the river were $\mathrm{NH}_{3}-\mathrm{N}, \mathrm{TP}$ and $\mathrm{BOD}_{5}$ and that different pollutants had different variation trends (Figure 3): the contribution of BOD 5 to the WPI initially increased from $13 \%$ in 1988 to $22 \%$ in 1994 but then declined after 1995 ; the contribution of $\mathrm{NH}_{3}-\mathrm{N}$ 
gradually increased from $12 \%$ in 1988 to $63 \%$ in 2009 ; the contribution of TP decreased from $64 \%$ in 1988 to $25 \%$ in 2009 .

Figure 3 also indicates that the industrial effluent pollutants, e.g., petroleum and heavy metals, significantly affected the water quality. The contribution of petroleum varied between $5.3 \%$ and $18.3 \%$ before 2000 , sharply decreased to $0.6 \%$ in 2001 , and then stayed at a low level. Heavy metals had some effects on WPI before 1997, whereas V-ArOH had some effects on WPI before 2005. However, the effects of heavy metals and $\mathrm{V}-\mathrm{ArOH}$ have become negligible in recent years.

\subsection{Water Quality vs. Pollutant Load Discharges}

Since $\mathrm{BOD}_{5}, \mathrm{NH}_{3}-\mathrm{N}$ and $\mathrm{TP}$ are the main pollutants in the river, their variations were further investigated. As observed in Figure 4, the annual average concentrations of the three pollutants followed different temporal trends: BOD 5 increased for 1985-1994 and then gradually decreased, reaching a concentration of $16.6 \mathrm{mg} / \mathrm{L}$ in 2009 ; $\mathrm{NH}_{3}-\mathrm{N}$ increased for $1985-1991$, remained relatively stable for 1992-1999, and then gradually increased; while TP decreased continuously after 1988.

Figure 4. Water quality and pollutant loads discharged in the Shenzhen River. (a) BOD5.

(b) $\mathrm{NH}_{3}-\mathrm{N}$. (c) TP.
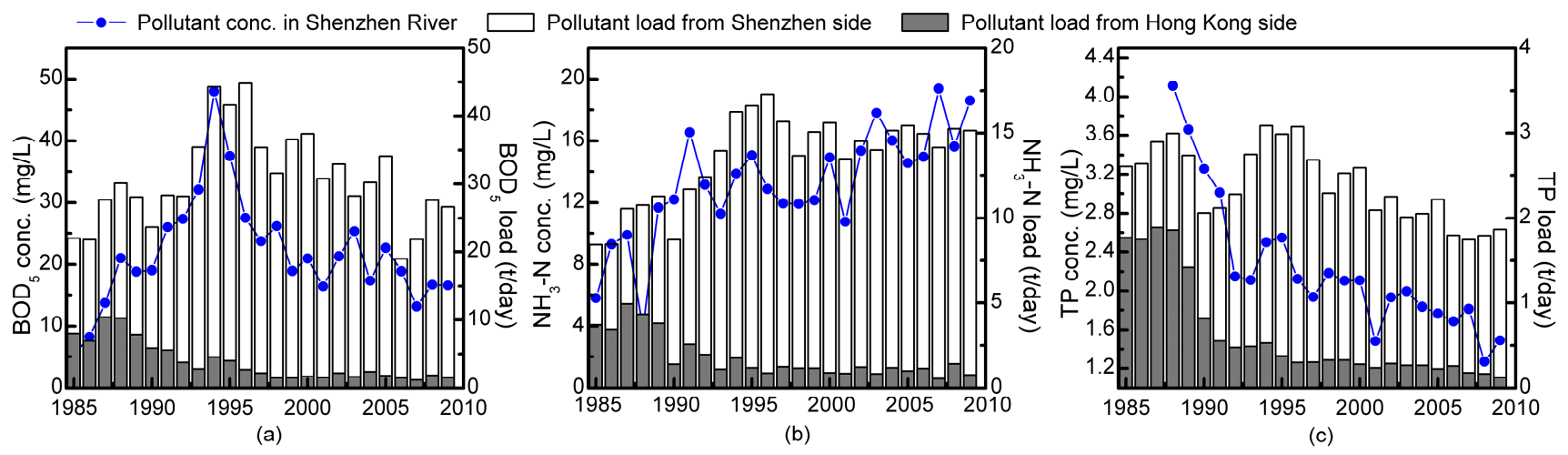

The temporal changes in water quality were mainly caused by the changes of the pollutant load discharges into the river from Shenzhen and Hong Kong. The indiscriminate discharge of livestock waste from the Hong Kong side was an important pollution source of the Shenzhen River before 1989 [24]. With the implementation of the Livestock Waste Control Scheme (LWCS) in 1987, many farmers on the Hong Kong side have ceased keeping livestock or have installed waste treatment facilities. Accordingly, the loads of $\mathrm{NH}_{3}-\mathrm{N}, \mathrm{TP}$ and $\mathrm{BOD}_{5}$ from Hong Kong rapidly decreased after 1989 (Figure 4). From Shenzhen, the loads of all three pollutants increased for 1985-1996; after which the TP and BOD5 loads then decreased, while the $\mathrm{NH}_{3}-\mathrm{N}$ loads remained relatively stable at approximately $13-15 \mathrm{t} /$ day after 1997.

The total pollutant load discharges can be estimated by summing the pollutant loads from the Shenzhen and Hong Kong sides. As observed in Figure 4, the total loads of the three main pollutants increased for 1985-1996; and then the $\mathrm{BOD}_{5}$ and $\mathrm{TP}$ loads decreased, while the $\mathrm{NH}_{3}-\mathrm{N}$ loads fluctuated at 13-16 t/day, for 1997-2009. Pearson's correlation analysis revealed that the pollutant concentration in the river was significantly correlated with the pollutant load discharges, with correlation coefficients of $0.743(p<0.01), 0.571(p<0.01)$ and $0.514(p<0.05)$ for $\mathrm{BOD}_{5}, \mathrm{NH}_{3}-\mathrm{N}$ and $\mathrm{TP}$, respectively. 


\subsection{Pollutant Load Generation vs. Removal}

Since the loads from Shenzhen accounted for $95 \%-99 \%$ of the total pollutant load discharges into the river after 1995, the pollutant load discharges on the Shenzhen side were further related to the pollutant load generation and removal. While the total pollutant load generation on the Shenzhen side increased over the study period, slowing after 2006 (Figure 5), the total pollutant load removal on the Shenzhen side slowly increased until 1996, rapidly increased from 1997-2006, and stabilized after 2006. Therefore, from 1985-1996, the pollutant load discharges from Shenzhen increased as the pollutant load generation increased faster than the pollutant load removal. From 1997-2009, the BOD 5 and TP load discharges decreased as the load removal of the two pollutants increased faster than the load generation, while the $\mathrm{NH}_{3}-\mathrm{N}$ load discharges followed a slightly increasing trend as the $\mathrm{NH}_{3}-\mathrm{N}$ load generation increased slightly faster than the load removal.

Figure 5. Pollutant load generation and removal on the Shenzhen side. (a) BOD 5 . (b) $\mathrm{NH}_{3}-\mathrm{N}$. (c) TP.
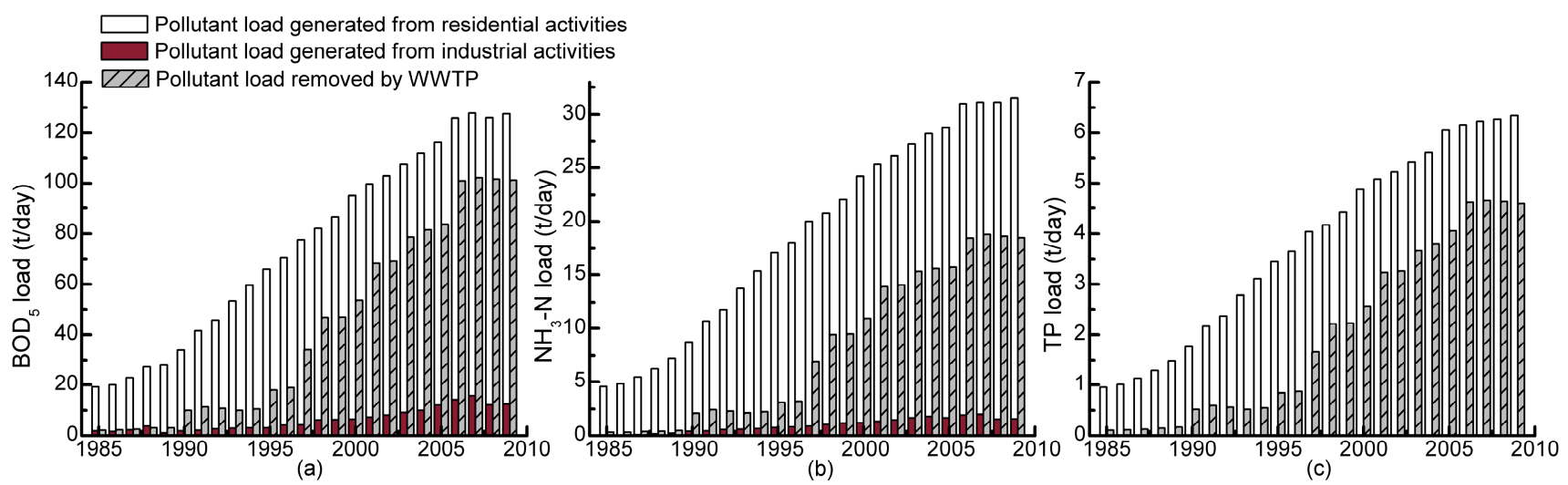

The main sources of water pollution in the catchment include industrial and domestic wastewater. Only the $\mathrm{BOD}_{5}$ and $\mathrm{NH}_{3}-\mathrm{N}$ sources were further analyzed in this study for lack of TP load generation data from industrial activities. As shown in Figure 5, $\mathrm{NH}_{3}-\mathrm{N}$ and $\mathrm{BOD}_{5}$ load generation from residential activities increased dramatically from 1985-2005, slowing after 2006. In contrast, $\mathrm{NH}_{3}-\mathrm{N}$ and $\mathrm{BOD}_{5}$ load generation from industrial activities increased slightly from 1985-2007 and decreased slightly after 2008. Figure 5 also indicates that the pollutant load generation from residential activities was the main source of pollution in the catchment.

\subsection{Capacity for Pollutant Load Removal}

The pollutant load removal was attributed to the capacity and efficiency of the wastewater facilities in the catchment. Only a small amount of wastewater was treated by WWTPs or transferred outside the catchment before 1995, but the amount increased rapidly from 1996-2006 (Figure 6a). In addition, the pollutant removal efficiency of WWTPs increased significantly after 1995 (Figure 6b). However, WWTPs have different removal efficiencies for different pollutants. For example, the removal efficiencies of $\mathrm{BOD}_{5}$ and $\mathrm{TP}$ have increased to approximately $90 \%$ and $80 \%$, respectively, while the removal efficiency of $\mathrm{NH}_{3}-\mathrm{N}$ remains lower than $60 \%$ (Figure $6 \mathrm{~b}$ ). These differences resulted in different temporal trends in load discharges of $\mathrm{BOD}_{5}, \mathrm{TP}$ and $\mathrm{NH}_{3}-\mathrm{N}$. 
Figure 6. Capacity of wastewater facilities in the catchment. (a) Wastewater collection, transfer and treatment. (b) Pollutant removal efficiency.

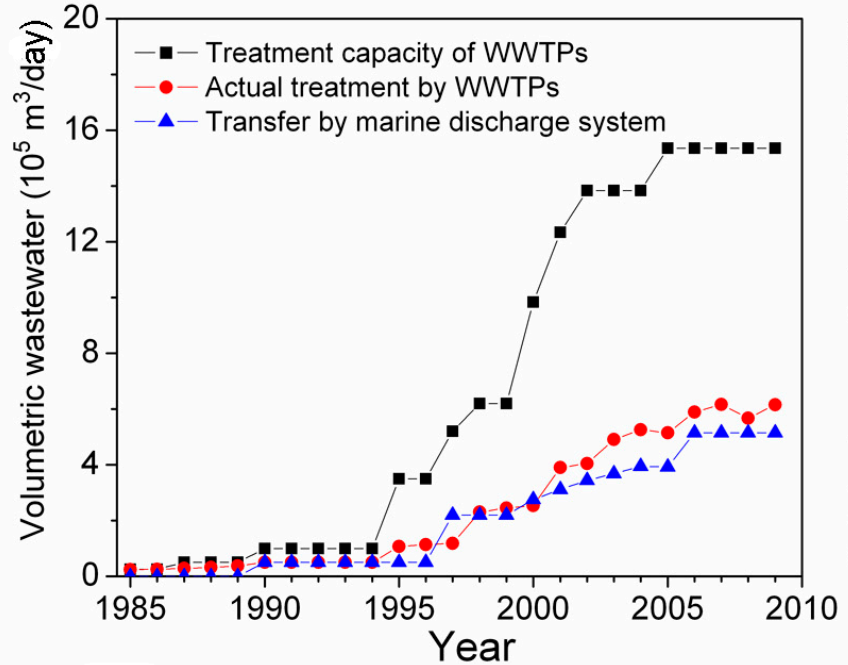

(a)

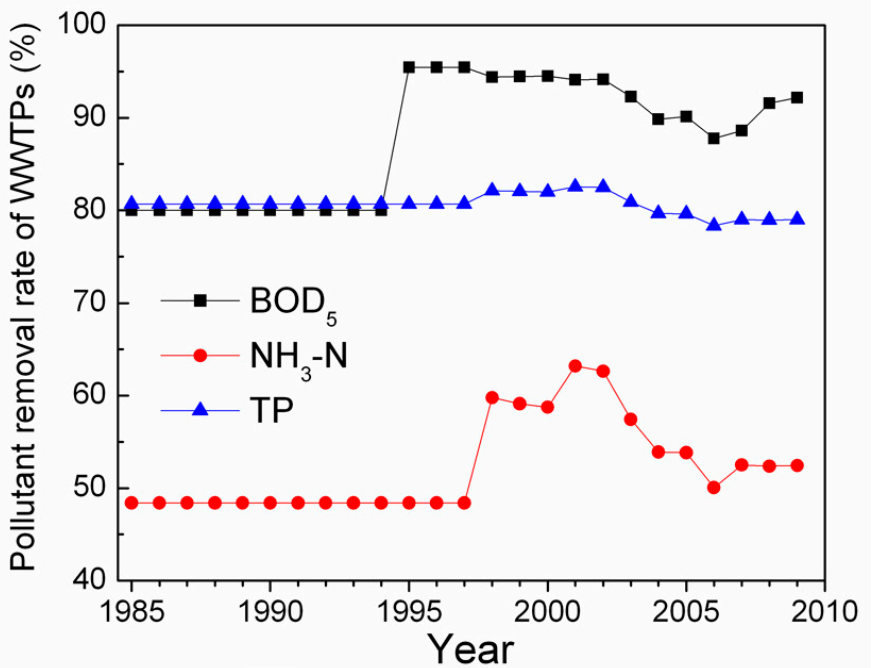

(b)

\section{Discussion}

\subsection{Water Pollution Characteristics during Urbanization}

Water pollution in the Shenzhen River has undergone a deterioration stage and improvement stage. As shown in Figure 5, the period of 1985-1995 is identified as a deterioration stage as the pollutant load generation increased faster than the pollutant load removal, while the period of 1996-2009 is identified as an improvement stage as the load removal increased faster than the load generation.

In both stages, water quality management in the catchment was under the pressure of rapid increases in both population and economy. For example, the average annual growth rate of GRP in the catchment for 1985-1995 and 1996-2009 was 30.3\% and 12.6\%, respectively; and the average annual growth rate of population for 1985-1995 and 1996-2009 was 14.3\% and 4.5\%, respectively. The pollutant load generation from residential activities was the main source of pollution in the catchment during rapid urbanization (Figure 5). For the period of 1996-2009, industry-derived petroleum and heavy metal pollution had been well controlled and domestic-derived water quality parameters (e.g., $\mathrm{BOD}_{5}, \mathrm{NH}_{3}-\mathrm{N}$ and TP) also improved greatly, however still had a high rate of non-compliance with water quality objectives.

\subsection{Effects of Socio-Economic Measures}

\subsubsection{Socio-Economic Measures}

Over the past three decades many socio-economic measures have been implemented in the Shenzhen River catchment. Three measures have had particularly significant effects on water quality improvement (Table 1):

(a) "Deadline requirements for pollution control" may suspend the operations of or close an enterprise or institution that has caused severe pollution to water bodies but has failed to adhere to the specified reduction goals by the deadline $[26,27]$. 
(b) "Centralized control of waste" was first instituted in China in 1999, requiring all levels of government to generate economies of scale and improve efficiency in waste disposal $[14,26]$. Based on this principle, ecological industrial parks are encouraged, in which businesses cooperate with each other and the local community in an attempt to reduce waste and pollution and efficiently share resources (such as information, materials, water, energy, infrastructure, and natural resources).

(c) To accelerate the transformation of economic development and promote industrial restructuring and upgrading, the local government has compiled the "catalog of industrial structure adjustment" annually since 1993 [28], in which the industries are categorized into three groups: encouraged, restricted, and prohibited. The prohibited industries include printing and dyeing, tinning, plating, and eight other labor-intensive industries. According to these catalogs, the industries with high labor productivity and low pollution emission were encouraged to develop, e.g., the cultural industry, the electronic information industry, the biotechnology and pharmaceutical industry, and the advanced material and new energy industry.

Table 1. Pollution control measures in the Shenzhen River catchment [23].

\begin{tabular}{|c|c|c|c|}
\hline Measures & Name & Year & Description \\
\hline \multirow[t]{5}{*}{$\begin{array}{l}\text { Socio-economic } \\
\text { measure }\end{array}$} & $\begin{array}{l}\text { Deadline } \\
\text { requirements for } \\
\text { pollution control }\end{array}$ & 1998 & $\begin{array}{l}\text { A total of } 173 \text { companies that had severely } \\
\text { polluted water bodies were required to reduce } \\
\text { pollution by the deadline, and } 43 \text { were ordered } \\
\text { to close down. }\end{array}$ \\
\hline & \multirow{3}{*}{$\begin{array}{l}\text { Centralized control } \\
\text { of waste }\end{array}$} & 1999 & $\begin{array}{l}\text { Focusing on petroleum discharge control, } \\
336 \text { companies were examined. }\end{array}$ \\
\hline & & 2004 & $\begin{array}{l}\text { Focusing on both } \mathrm{V}-\mathrm{ArOH} \text { and } \\
\text { petroleum discharge control. }\end{array}$ \\
\hline & & 2000 & $\begin{array}{l}\text { An electroplating park was established, and } \\
\text { all wastewater from the electroplating industry } \\
\text { can now be effectively collected and treated in } \\
\text { the park before discharge. }\end{array}$ \\
\hline & $\begin{array}{l}\text { Catalog of industrial } \\
\text { structure adjustment }\end{array}$ & 1993-2009 & $\begin{array}{l}\text { The industries were categorized into three } \\
\text { groups: encouraged, restricted, and prohibited. } \\
\text { Industries with high labor productivity and low } \\
\text { pollution emission were encouraged to develop. }\end{array}$ \\
\hline \multirow[t]{3}{*}{$\begin{array}{l}\text { WWTP construction } \\
\& \text { technology } \\
\text { improvement }\end{array}$} & Binhe WWTP & 1985-1995 & $\begin{array}{l}\text { Wastewater treatment capacity: } 2.5 \times 10^{4} \mathrm{~m}^{3} / \text { day } \\
\text { in } 1985,3.0 \times 10^{5} \mathrm{~m}^{3} / \text { day in } 1995 \text {; actual } \\
\text { wastewater treatment: } 1.1 \times 10^{5} \mathrm{~m}^{3} / \text { day in } 1995 \text {. }\end{array}$ \\
\hline & Luofang WWTP & 1998-2002 & $\begin{array}{l}\text { Wastewater treatment capacity: } 1.0 \times 10^{5} \mathrm{~m}^{3} / \text { day } \\
\text { in } 1998,3.5 \times 10^{5} \mathrm{~m}^{3} / \text { day in } 2002 \text {; actual } \\
\text { wastewater treatment: } 2.2 \times 10^{5} \mathrm{~m}^{3} / \text { day in } 2002 \text {. }\end{array}$ \\
\hline & Caopu WWTP & 2003 & $\begin{array}{l}\text { Wastewater treatment capacity: } \\
1.5 \times 10^{5} \mathrm{~m}^{3} / \text { day; actual wastewater } \\
\text { treatment: } 5.0 \times 10^{4} \mathrm{~m}^{3} / \text { day. }\end{array}$ \\
\hline
\end{tabular}


Table 1. Cont.

\begin{tabular}{llll}
\hline \multicolumn{1}{c}{ Measures } & \multicolumn{1}{c}{ Name } & Year & \multicolumn{1}{c}{ Description } \\
\hline $\begin{array}{l}\text { Wastewater transfer } \\
\begin{array}{l}\text { and marine } \\
\text { discharge system }\end{array}\end{array}$ & Stage I, II \& III & $1990-2001$ & $\begin{array}{l}\text { Wastewater transfer capacity: } 5.0 \times 10^{4} \mathrm{~m}^{3} / \text { day } \\
\text { in } 1990,7.4 \times 10^{5} \mathrm{~m}^{3} / \text { day in } 2001 ; \text { actual } \\
\text { wastewater transfer } 2.4 \times 10^{5} \mathrm{~m}^{3} / \text { day in } 2001 .\end{array}$ \\
\hline $\begin{array}{l}\text { Sewer system } \\
\text { improvement }\end{array}$ & $\begin{array}{l}\text { For Binhe WWTP } \\
\text { collection area }\end{array}$ & \multirow{2}{*}{1999} & $\begin{array}{l}\text { Wastewater collection capacity: } \\
1.5 \times 10^{5} \mathrm{~m}^{3} / \text { day. }\end{array}$ \\
\hline & $\begin{array}{l}\text { Wastewater transfer } \\
\text { and marine } \\
\text { discharge system } \\
\text { collection area }\end{array}$ & 2003 & $\begin{array}{l}\text { Wastewater collection capacity: } \\
2.8 \times 10^{5} \mathrm{~m}^{3} / \text { day. }\end{array}$ \\
& $\begin{array}{l}\text { For Luofang WWTP } \\
\text { collection area }\end{array}$ & 2004 & $\begin{array}{l}\text { Wastewater collection capacity: } \\
2.6 \times 10^{5} \mathrm{~m}^{3} / \text { day. }\end{array}$ \\
\cline { 2 - 4 } & $\begin{array}{l}\text { For Caopu WWTP } \\
\text { collection area }\end{array}$ & 2006 & $\begin{array}{l}\text { Wastewater collection capacity: } \\
1.5 \times 10^{5} \mathrm{~m}^{3} / \text { day. }\end{array}$ \\
\hline
\end{tabular}

\subsubsection{Effects of "Deadline Requirements" and "Centralized Control"}

In the 1980s, many industries with high pollution emission, e.g., paper and paper-board, chemical raw materials and products, dyeing and metalwork were introduced into the Shenzhen River catchment without appropriate pollution control regulations/measures. These industries contributed organic, petroleum and heavy metal pollution to the river.

The "deadline requirements for pollution control" for petroleum and V-ArOH were implemented in Shenzhen in 1999 and 2004, respectively. The effect of these measures can be seen in a decrease in pollutant levels one to two years after implementation, and the contribution of petroleum and $\mathrm{V}-\mathrm{ArOH}$ to the WPI has become negligible since 2001 and 2005, respectively (Figure 3).

The electroplating industry is a dominant industry type in Shenzhen and typically causes serious heavy metal pollution. To solve this problem, in 2000 an electroplating industry park was established in Shenzhen and the related factories relocated to the park, allowing industry wastewater to be effectively collected and treated in the park before discharge. The implementation of this "centralized control of waste" measure may be one of the reasons for the low concentration level of heavy metal in the recent decade (Figure 3).

\subsubsection{Effects of Industrial Structure Adjustment}

With the implementation of the "catalog of industrial structure adjustment" the proportion of secondary industry decreased. Although the average annual growth rate of GRP in the catchment was as high as $18.4 \%$, the growth rate of the GRP in the secondary industry was only $14.9 \%$ (Figure $7 \mathrm{a}$ ). In particular, the proportion of GRP from the secondary industry decreased dramatically from $49.4 \%$ in 1990 to $16.6 \%$ in 2009. Furthermore, the decrease in GRP proportion of the labor intensive secondary industry resulted in the decrease in the pollutant generation per GRP in the secondary industry. The secondary industry can be further subdivided into labor-, technology- and capital-intensive secondary industries according to the dominant production process. As shown in Figure $7 \mathrm{~b}$, the GRP of the technology-intensive secondary industry increased faster than that of the labor-intensive industry, which 
caused the GRP proportion of technology-intensive industry to increase while that of labor-intensive industry to decrease from 1990-2009. As the pollutant generation per GRP in the technology-intensive industry is much lower than that in the labor-intensive secondary industry, the changes in the secondary industry structure decreased the pollutant generation per GRP in the secondary industry. Therefore, the industrial structure adjustment greatly reduced the growth rate of the pollutant load generation from the secondary industry (Figure 5).

Figure 7. GRP and labor productivity in various industries. (a) GRP in various industries.

(b) GRP in various secondary industries. (c) Labor productivity in various industries.
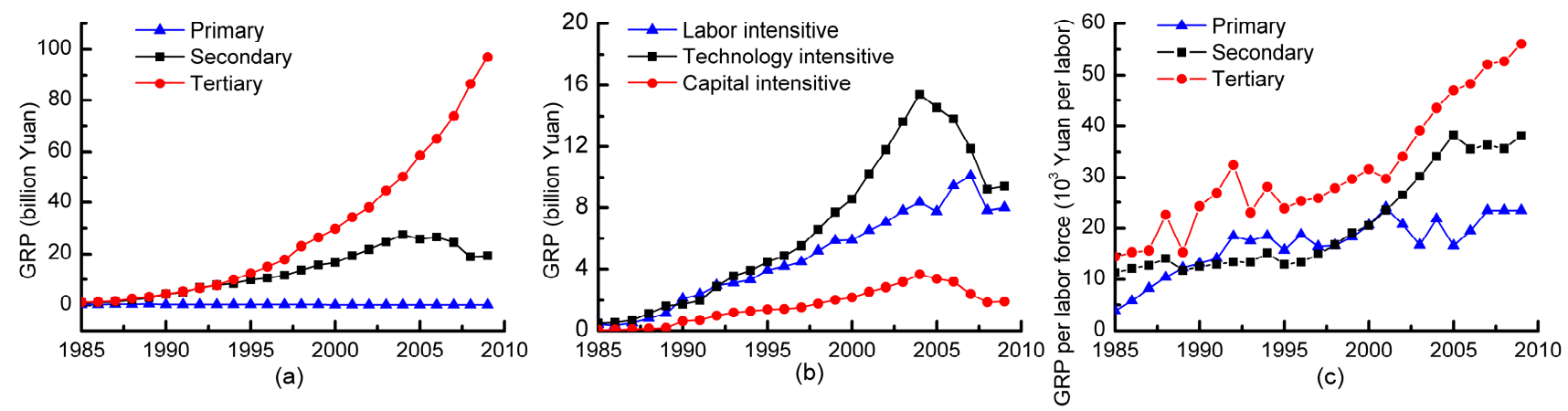

Furthermore, industrial structure adjustment can also greatly increase the labor productivity in the catchment and decrease the growth rates of the population and the relevant residential pollutant load. The average annual growth rate of population (8.8\%) for 1985-2009 was much lower than that of GRP (20.4\%), indicating an increase in the labor productivity during the urbanization process. This trend can be explained by the increase in labor productivity in various industries over the last three decades (Figure 7c). In addition, between 1990 and 2009, the proportion of the secondary industry decreased, while that of the tertiary industry increased. As the labor productivity in the tertiary industry was higher than that in the secondary industry (Figure 7c), the increase of the tertiary industry proportion resulted in an improvement of labor productivity.

\subsection{Effects of Wastewater Infrastructure Development}

\subsubsection{Wastewater Infrastructure}

The following wastewater infrastructure has been developed in the northern catchment: WWTPs, wastewater transfer and marine discharge system improvement and sewer system (Table 1 and Figure 6):

(a) Before 1994, Binhe WWTP was the only WWTP in the catchment (Figure 1). This WWTP was equipped with secondary treatment; its $\mathrm{BOD}_{5}, \mathrm{NH}_{3}-\mathrm{N}$ and $\mathrm{TP}$ removal rates were $80 \%, 48 \%$ and $81 \%$, respectively; its volumetric treatment capacity was less than $5.0 \times 10^{4} \mathrm{~m}^{3} /$ day. Two WWTPs, Luofang WWTP with secondary treatment and Caopu WWTP with advanced primary treatment (Figure 1), were constructed and then upgraded between 1996 and 2003. In 2005, the total volumetric treatment capacity in the northern catchment rapidly increased to $1.5 \times 10^{6} \mathrm{~m}^{3} /$ day, while the $\mathrm{BOD}_{5}, \mathrm{NH}_{3}-\mathrm{N}$ and TP removal rates increased to $92 \%, 57 \%$ and $81 \%$, respectively. 
(b) A wastewater transfer and marine discharge system was constructed in 1990 and $5.0 \times 10^{4} \mathrm{~m}^{3} /$ day of wastewater was transferred outside of the Shenzhen River catchment and discharged into the sea through a long-distance discharge pipe. The system was gradually enlarged between 1997 and 2001, and its transfer capacity increased to $7.4 \times 10^{5} \mathrm{~m}^{3} /$ day by 2001 .

(c) A large amount of wastewater in the catchment could not be collected and conveyed to the WWTPs due to non-existent or low-efficiency sewer systems during urbanization. Several projects had been carried out to retrofit or improve the sewer systems in the catchment over 1999-2006, and the amount of wastewater actually collected by the sewer system increased from $4.4 \times 10^{5} \mathrm{~m}^{3} /$ day in 1999 to $9.4 \times 10^{5} \mathrm{~m}^{3} /$ day in 2006 .

\subsubsection{Limitations of Wastewater Infrastructure}

Although the wastewater infrastructure had significant effects on water quality improvement during urbanization, it was unable to effectively collect and dispose of all wastewater in the catchment. This inability was caused by the following:

(1) The construction of wastewater facilities lagged behind population and economic growth in the early stages of urbanization (before 1995). In the study area, socio-economic planning and wastewater facilities planning are performed by the Shenzhen Development and Reform Commission (SZDRC) and Shenzhen Municipal Water Affairs Bureau (SZWAB), respectively. The socio-economic planners of SZDRC are not expected to fully apprehend the capacity limitations of existing/future wastewater facilities in their decision-making process and usually assume that facilities construction can match the pace of socio-economic growth, while wastewater facilities planners of SZWAB do not fully account for the extent of rapid socio-economic development in decision making. Facilities planners usually estimate certain socio-economic growth potentials in their planning, however the facilities planners may over- or under-estimate the growth and fail to make timely adjustment in facilities development. Therefore, wastewater generation and treatment capacity may be mismatched during rapid urbanization [29]. These mismatches caused water quality deterioration in the early stage of urbanization.

(2) The sewer network construction lagged behind the construction of WWTPs in the catchment. The wastewater treatment capacity of WWTPs increased much faster than the amount of wastewater actually collected by the sewer system in the catchment (Figure 6a). One reason is that the local government focused on improving wastewater treatment capacity by constructing WWTPs. However, constructing a sewer network is more difficult and requires more time to construct, and due to the delay in construction the wastewater collection capacity increased slower than the treatment capacity.

(3) The existing sewer networks were operated at a low efficiency level. Most of the early developed areas in the catchment are densely populated, and overcrowded multi-story buildings are usually prevalent in these areas. While the buildings provide cheap accommodation for the massive number of workers immigrating from other Chinese cities or villages, they usually have poorly installed pipelines which result in the mixing of sewage flows with rainfall runoff. In addition, to fully utilize the indoor living space, local residents alter balconies in the buildings to re-equip them for toilet, kitchen or laundry use, leading to sewage discharge into the river via rainwater 
pipes. Due to the poor environmental management and environmentally harmful behavior, wastewater cannot be efficiently collected into the existing sewer systems.

(4) The WWTPs have relatively low removal efficiencies for nutrient pollutants. The existing WWTPs in the Shenzhen River are equipped with secondary or advanced primary treatment technology. The WWTPs have high removal rates for organic matter, such as $\mathrm{BOD}_{5}$, but are not as effective in removing nutrient substances, such as nitrogen and phosphorus, and unfortunately these nutrient substances are predominant pollutants in densely populated catchments such as the Shenzhen River catchment. For example, the $\mathrm{NH}_{3}-\mathrm{N}$ pollutant removal rate of the WWTPs in the catchment was only $55 \%$ in 2009 . Therefore, although $\mathrm{BOD}_{5}$ has significantly decreased, $\mathrm{NH}_{3}-\mathrm{N}$ has remained at a high level since 1995.

\subsection{Solutions on Water Quality Changes}

Although the water quality of the Shenzhen River has improved greatly since 1996, some domestic-derived water quality parameters still have a high rate of non-compliance with water quality objectives. For example, $\mathrm{NH}_{3}-\mathrm{N}$ and $\mathrm{TP}$ of the river in 2009 were three and eight times higher, respectively, than the corresponding maximum permitted concentrations prescribed by the Environmental Quality Standard for Surface Water in China (GB 3838-2002). To satisfy the water quality requirement, further multifaceted approaches including wastewater infrastructure investment, socio-economic policies regulation and increasing environmental awareness, are required and discussed below.

\subsubsection{Wastewater Infrastructure Construction}

Wastewater infrastructure construction lagged behind the population and economic growth during rapid urbanization of the area, and the wastewater infrastructure still needs to be further improved in the future. The sewer networks should be constructed timely and revitalized regularly in line with urbanization. To reduce the nitrogen and phosphorus discharge, wastewater treatment facilities should be upgraded to improve their nitrogen and phosphorus removal efficiencies.

In addition to the centralized wastewater infrastructure, the construction of decentralized small WWTPs should also be promoted. These infrastructures have lower cost, higher ecological value and additional public benefits and are considered sustainable approaches for water environment. For example, Organica Food Chain Reactor is a decentralized and "living" WWTP, which can maximize the decomposition of contaminants such as nitrogen and phosphorus, and minimize space and energy in situ [30].

\subsubsection{Socio-Economic Policies Regulation}

The social-economic measures (e.g., "deadline requirements for pollution control", "centralized control of pollutant") have made great progress in addressing industry-derived petroleum and heavy metal pollution in the catchment. Local government is also reliant on economic measures such as industrial structure adjustment, which largely reduced the water consumption and wastewater generation in economic and residential activities. However, socio-economic policies still need to be promoted in the future to obtain sustainable development of economy and environment. Besides the administrative 
regulation policies (e.g., industrial structure adjustment), economic incentives and financial policies (e.g., water tariff adjustment, trade of pollutant emission rights) should be implemented to encourage industries to prevent or reduce pollution at the source.

\subsubsection{Increasing Environmental Awareness}

As mentioned in Section 4.3.2, the lack of environmental awareness of local residents is one of the main reasons for low operation efficiency of the existing sewer networks. In order to increase the environmental awareness, the local government should increase the public education level, disclose environmental information and promote public participation in environmental protection. The enterprises should be encouraged to take part in preventive approaches such as ISO 14000, environmental labeling, and cleaner production. In addition, technology support for the creation of neighborhood-based water purification installations should also be promoted to help residents and enterprises effectively reduce pollutant generation/emission and reuse wastewater.

\subsubsection{Integrated Measures on the Water Environment}

Both socio-economic measures and infrastructure construction are necessary to improve water quality in a rapidly urbanizing catchment. To achieve economic and environmental sustainability in the catchment, planners and policy makers across different sectors must consult with each other and jointly make decisions on integrated planning for socio-economic development and wastewater facilities improvement.

\section{Conclusions}

In this paper, we characterized the water quality changes and identified the factors that determine the changes in the Shenzhen River catchment during rapid urbanization. In the early stage of urbanization (1985-1995) water quality deteriorated rapidly due to the construction of wastewater infrastructure lagged behind the population and economic growth. Although the population and economy continued to grow in the second stage of urbanization (1996-2009), water quality gradually improved due to the implementation of comprehensive measures for pollution control, and rapid increases in domestic pollution discharge were identified as the major causes of water quality deterioration. Industry-derived petroleum and heavy metal pollution were well controlled; however, the domestic-derived water quality parameters (e.g., $\mathrm{BOD}_{5}, \mathrm{NH}_{3}-\mathrm{N}$ and $\mathrm{TP}$ ) still had a high rate of non-compliance with water quality objectives.

Although the wastewater infrastructure had significant effects on water quality improvement during urbanization, some wastewater could not be efficiently collected and treated before discharge due to the delay in sewer system construction, poor environmental management and environmentally harmful behaviors of residents in the early developed areas. Results also indicate that socio-economic measures had significant effects on water quality improvement. The industry-related pollutants, e.g., heavy metal, petroleum and $\mathrm{V}-\mathrm{ArOH}$, have been well controlled by enforcing "deadline requirements for pollution control" and "centralized control of pollutant" in the catchment. In addition, industrial structure adjustment can not only directly reduce pollutant generation from secondary industry by decreasing 
pollutant load per GRP in the industries but also indirectly reduce pollutant generation from residential activities by increasing labor productivity.

To avoid repeating past mistakes and to institute a sustainable development regime, we suggest that: (1) the wastewater infrastructure should be constructed timely and revitalized regularly in line with the urbanization, and wastewater treatment facilities should be upgraded to improve their nitrogen and phosphorus removal efficiencies; (2) both administrative regulation policies, economic incentives and financial policies should be implemented to encourage industries to prevent or reduce the pollution at the source; (3) the environmental awareness and the education level of local population should be increased; (4) planners and policy makers across different sectors must consult with each other and jointly make decisions on integrated planning for socio-economic development and wastewater facilities improvement.

\section{Acknowledgments}

This research was supported by the European Community's Seventh Framework Programme under grant agreement NO. PIIF-GA-2008-220448 and Project of Shenzhen Municipal Development and Reform Commission of China (301200800174-01).

\section{Author Contributions}

Hua-peng Qin contributed to the development of the idea and participated in all phases. Qiong Su conducted the data collection/analysis and manuscript preparation. Soon-Thiam Khu helped perform the analysis with constructive discussions. Nv Tang helped improve the figures and manuscript. All authors have read and approved the final manuscript.

\section{Conflicts of Interest}

The authors declare no conflict of interest.

\section{References}

1. Lehmann, S. Can rapid urbanization ever lead to low carbon cities? The case of Shanghai in comparison to Potsdamer Platz Berlin. Sustain. Cities Soc. 2012, 3, 1-12.

2. Rana, M.M.P. Urbanization and sustainability: Challenges and stragety for sustainable development. Environ. Dev. Sustain. 2011, 13, 237-256.

3. Zhao, S.; Da, L.; Tang, Z.; Fang, H.; Song, K.; Fang, J. Ecological consequences of rapid urban expansion: Shanghai, China. Front. Ecol. Environ. 2006, 4, 341-346.

4. Ren, W.W.; Zhong, Y.; Meligrana, J.; Anderson, B.; Watt, W.E.; Chen, J.K.; Leung, H.L. Urbanization, landuse, and water quality in Shanghai 1947-1996. Environ. Int. 2003, 29, 649-659.

5. Chang, H. Spatial and temporal variations of water quality in the Han River and its tributaries, Seoul, Korea, 1993-2002. Water Air Soil Pollut. 2005, 161, 267-284.

6. Kannel, P.R.; Lee, S.; Kanel, S.R.; Khan, S.P.; Lee, Y.S. Spatial-temporal variation and comparative assessment of water qualities of urban river system: A case study of the River Bagmati (Nepal). Environ. Monitor. Assess. 2007, 129, 433-459. 
7. Boeder, M.; Chang, H. Multi-scale analysis of oxygen demand trends in an urbanizing Oregon watershed, USA. J. Environ. Manag. 2008, 87, 567-581.

8. Ferrier, R.C.; Edwards, A.C.; Hirst, D.; Littlewood, I.G.; Watts, C.D.; Morris, R. Water quality of Scottish rivers: Spatial and temporal trends. Sci. Total Environ. 2001, 265, 327-342.

9. He, H.M.; Zhou, J.; Wu, Y.J.; Zhang, W.C.; Xie, X.P. Modelling the response of surface water quality to the urbanization. J. Environ. Manag. 2008, 86, 731-749.

10. Groppo, J.D.; de Moraes, J.M.; Beduschi, C.E.; Genovez, A.M.; Martinelli, L.A. Trend analysis of water quality in some rivers with different degrees of development within the São Paulo State, Brazil. River Res. Appl. 2008, 24, 1056-1067.

11. Ma, J.Z.; Ding, Z.Y.; Wei, G.X.; Zhao, H.; Huang, T.M. Sources of water pollution and evolution of water quality in the Wuwei basin of Shiyang river, Northwest China. J. Environ. Manag. 2009, 90, 1168-1177.

12. Duh, J.D.; Shandas, V.; Chang, H.; George, L.A. Rates of urbanisation and the resiliency of air and water quality. Sci. Total Environ. 2008, 400, 238-256.

13. Qin, H.P.; Su, Q.; Khu, S.T. An integrated model for water management in a rapidly urbanizing catchment. Environ. Model. Softw. 2011, 26, 1502-1514.

14. Zhang, K.M.; Wen, Z.G. Review and challenges of policies of environmental protection and sustainable development in China. J. Environ. Manag. 2008, 88, 1249-1261.

15. Shao, W. Effectiveness of water protection policy in China: A case study of Jiaxing. Sci. Total Environ. 2010, 408, 690-701.

16. Su, S.L.; Li, D.; Zhang, Q.; Xiao, R.; Huang, F.; Wu, J.P. Temporal trend and source apportionment of water pollution in different functional zones of Qiantang River, China. Water Res. 2011, 45, 1781-1795.

17. Weng, Q. A historical perspective of river basin management in the Pearl River Delta of China. J. Environ. Manag. 2007, 85, 1048-1062.

18. Miljašević, D.; Milanović, A.; Brankov, J.; Radovanović, M. Water quality assessment of the Borska Reka river using the WPI (water pollution index) method. Arch. Biol. Sci. 2011, 63, 819-824.

19. Nikolaidis, C.; Mandalos, P.; Vantarakis, A. Impact of intensive agricultural practices on drinking water quality in the EVROS Region (NE GREECE) by GIS analysis. Environ. Monitor. Assess. 2008, 143, 43-50.

20. $\mathrm{Su}, \mathrm{Q}$.; Qin, H.P. Environmental and ecological impacts of water supplement schemes in a heavily polluted estuary. Sci. Total Environ. 2014, 472, 704-711.

21. Liu, N.; Lu, R.F. Water Environmental Management in Shenzhen River and Deep Bay, 1st ed.; China Water Power Press: Beijing, China, 2006. (in Chinese)

22. Census and Statistical Bureau of Shenzhen (CSBSZ). Statistical Year Book of Shenzhen 1985-2009; China Statistical Press: Beijing, China, 2010. (in Chinese)

23. Environmental Protection Bureau of Shenzhen (EPBSZ). Water Quality Report of Shenzhen 1985-2009; EPBSZ: Shenzhen, China, 2010. (in Chinese)

24. Environmental Protection Department of Hong Kong (EPDHK). River Water Quality in Hong Kong 1985-2009. Available online: http://www.gov.hk/en/residents/environment/water/riverwater.htm (accessed on 18 October 2014). 
25. Environmental Protection Department of Hong Kong (EPDHK). Guideline for Estimating Sewage for Infrastructure Planning; EPDHK: Hong Kong, China, 2005.

26. MacBean, A. China's Environment: Problems and Policies. World Econ. 2007, 30, 292-307.

27. Zhang, K.M.; Wen, Z.G.; Peng, L.Y. Environmental policies in China: Evolvement, feature and evaluation. China Popul. Resour. Environ. 2007, 17, 1-7.

28. Development and Reform Commission of Shenzhen (DRCSZ). Catalogue of industrial structure adjustment 1993-2009. Available online: http://www.szpb.gov.cn/fgzl/cydxml (accessed on 18 October 2014).

29. Qin, H.P.; Su, Q.; Khu, S.T. Assessment of environmental improvement measures using a novel integrated model: A case study of the Shenzhen River catchment, China. J. Environ. Manag. 2013, 114, 486-495.

30. Organica Food Chain Reactor. Lower infrastructure cost: Treating wastewater at the source eliminates the need for expensive infrastructure. Available online: http://www.organicawater.com/ solutions/advantages/lower-infrastructure-costs (accessed on 29 September 2014).

(C) 2014 by the authors; licensee MDPI, Basel, Switzerland. This article is an open access article distributed under the terms and conditions of the Creative Commons Attribution license (http://creativecommons.org/licenses/by/4.0/). 